\title{
ARTICLE
}

\section{Gamma survey in Fukushima prefecture right after the accident at Fukushima nuclear power plant}

\author{
Yoshitomo Uwamino $^{\mathrm{a}^{*}}$, Hiroshi Matsumura ${ }^{\mathrm{b}}$, Kiwamu Saito ${ }^{\mathrm{b}}$ and Jun Ishioka ${ }^{\mathrm{a}}$ \\ ${ }^{a}$ RIKEN, 2-1 Hirosawa, Wako-shi, Saitama-ken, 351-0198, Japan; ${ }^{b}$ High Energy Accelerator Research Organization (KEK), \\ 1-1 Oho, Tsukuba-shi, Ibaraki-ken, 305-0801, Japan
}

On March 15-17 and April 8, 2011, right after the accident at Fukushima nuclear power plant, $\gamma$-ray dose-rate distributions and spectra were measured on expressways in Fukushima and neighboring prefectures using an $\mathrm{NaI}(\mathrm{Tl})$ dosimeter and a $\mathrm{LaBr}_{3}$ spectrometer. A radioactive plume was observed near Koriyama-city on 15. Although the distributions of ${ }^{132} \mathrm{Te},{ }^{132} \mathrm{I},{ }^{134} \mathrm{Cs},{ }^{136} \mathrm{Cs}$, and ${ }^{137} \mathrm{Cs}$ resembled each other, the distribution of ${ }^{131} \mathrm{I}$ was different from the others. The dominant radionuclides of dose rate were ${ }^{132} \mathrm{Te}$ and ${ }^{132} \mathrm{I}$ on March $15-17$ and ${ }^{134} \mathrm{Cs}$ and ${ }^{137} \mathrm{Cs}$ on April 8. The initial distribution profile of the dose rate on March 15-17 remained on April 8, which showed the deposited radioactive material was not moved from the initial location and there was no additional effective deposition of radioactivity after March 15.

Keywords: Fukushima Daiichi Nuclear Power Plant; gamma-ray measurement; $\mathbf{L a B r}_{3}$ Spectrometer; expressway

\section{Introduction}

The accident at the Fukushima Daiichi Nuclear Power Plant caused by the enormous earthquake and subsequent tsunami on March 11, 2011, scattered a large amount of radionuclides in the Tohoku and Kanto areas. On the request of the Ministry of Education, Culture, Sports, Science and Technology to bring survey meters for the screening of the evacuees, we visited Fukushima city on March 14. At there we were asked by the Fukushima prefectural government to measure the dose rates along the expressways in Fukushima prefecture.

The detailed measured data were already published in reference 1 , and an article of interpretation of the data was posted on the KEK (High Energy Accelerator Research Organization) web site [2] and orally presented at a scientific meeting [3]. Here a digest of the published papers and some new data are shown.

\section{Measurement}

\subsection{Detectors}

A scintillation survey meter (Hitachi-Aloka TCS-161) was used for $\gamma$-ray dose rate measurement. It consists of a 2.5 -cm-diam. by 2.5 - $\mathrm{cm}$-long $\mathrm{NaI}(\mathrm{Tl})$ scintillator. The energy compensation circuit of it gives 1-cm dose equivalent value with accuracy better than $\pm 20 \%$ for $\gamma$-rays of energy higher than $50 \mathrm{keV}$.

*Corresponding author. Email: uwamino@riken.jp
A $\gamma$-ray portable spectrometer (Canberra IN1KL-1) with a 3.8-cm-diam. by 3.8-cm-long $\mathrm{LaBr}_{3}(\mathrm{Ce})$ scintillator was used for the spectrum measurement. This detector also gives the dose equivalent values.

Personal dosimeters (Thermo Scientific EPDMk2) were also used. They record the trend of exposure rate.

\subsection{Locations}

With these detectors we measured $\gamma$-rays along the roads, mostly expressways, shown as thick lines in Figure 1. On the roads the detectors was placed at the inside of the window to minimize the shielding effect of the car, and the dose rates were read at intervals of $1 \mathrm{~km}$.

At parking places we got off the car, and measured the dose rates and the spectra at open spaces far from the car. The detectors were placed $130 \mathrm{~cm}$ above the ground to keep the same height as the measurement on roads.

At 13:33 on March 15 we started Fukushima prefecture disaster headquarter building in Fukushima city, and took Tohoku expressway at Fukushima-nishi interchange (IC) to Koriyama junction (JCT). We drove Ban-etsu expressway, reached Iwaki-Yotsukura IC at 17:38, left expressway, and visited Yotsukura branch of Iwaki City Hall etc. We took expressway again at Iwaki-chuo IC at 18:37, and returned back Fukushima city at 20:59.

On March 16 we left Fukushima city at 11:41, drove Tohoku expressway to Shirakawa IC, visited Shimogo Town Hall, Aizuwakamatsu City Hall, and came back Fukushima city at 18:42. 


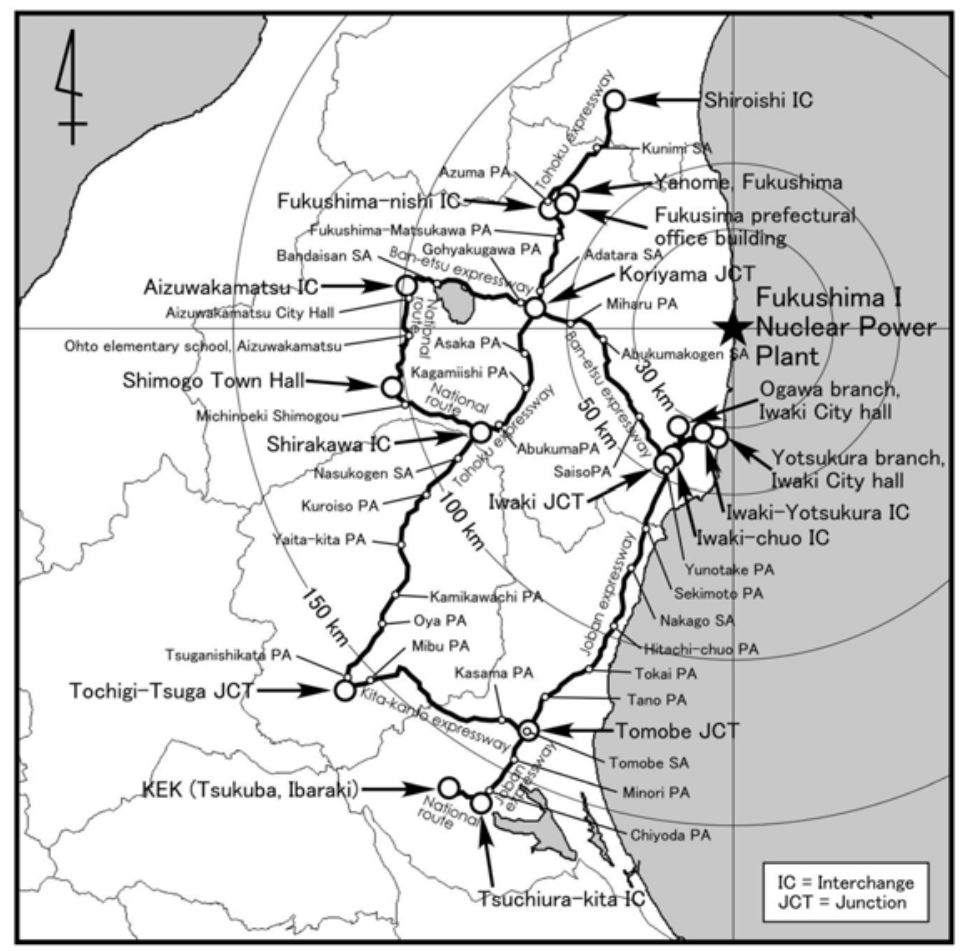

Figure 1. Route map of the $\gamma$-ray measurements [1].

On 17 we left Fukushima city at 10:53, drove Tohoku, Kita-Kanto and Joban expressway to Tsuchiura-kita IC, and arrive KEK in Tsukuba city at 16:24.

To measure the radionuclides distribution after a decay time of 3 weeks, we again started KEK on April 8. We drove Joban, Kita-Kanto, and Tohoku expressway to Shiroishi IC in Miyagi Pref., and came back along Tohoku expressway until Koriyama JCT, and used Ban-etsu and Joban expressway to Tsuchiura-kita IC.

\subsection{Analysis of $\gamma$-ray spectrum}

Total absorption peaks of $\gamma$-rays from ${ }^{132} \mathrm{Te},{ }^{132} \mathrm{I},{ }^{131} \mathrm{I}$, ${ }^{133} \mathrm{Xe},{ }^{134} \mathrm{Cs}$, ${ }^{136} \mathrm{Cs}$, and ${ }^{137} \mathrm{Cs}$ were observed in the spectra obtained with the $\mathrm{LaBr}_{3}$ detector as shown in Figure 2. The surface densities of these radionuclides were estimated with the ISOCS software [4] by assuming a uniform distribution of 100 -m radius on the ground.

Since the source conditions were not known, it was difficult to obtain accurate absolute values of radionuclide densities, only relative distributions were estimated.

The contributions of radionuclide in air were estimated with ISOCS. A 100-m-radius and 100-m-height uniform distribution above the ground was assumed, and the maximum effect of it was found to be $25 \%$ overestimation of the ${ }^{133} \mathrm{Xe} /{ }^{136} \mathrm{Cs}$ ratio when the contribution of the contaminated air was ignored. However, this error value was smaller than the necessary accuracy for the discussion in the next section.

\section{Results and discussion}

The $\gamma$-ray dose distributions measured on March 15 are shown in Figures 3 and $\mathbf{4}$. When we left Fukushima city, the dose rate was less than $0.1 \mu \mathrm{Sv} / \mathrm{h}$, which was the value of natural background. A radioactive plume that contained ${ }^{133} \mathrm{Xe},{ }^{132} \mathrm{Te},{ }^{132} \mathrm{I},{ }^{131} \mathrm{I},{ }^{134} \mathrm{Cs}$, and ${ }^{136} \mathrm{Cs}$ was first observed near Koriyama-higashi IC at 15:23, where the dose rate was $12.7 \mu \mathrm{Sv} / \mathrm{h}$. The dose rates in Iwaki city were approximately 2 to $3 \mu \mathrm{Sv} / \mathrm{h}$. When we returned to Fukushima city at 20:59, we found the city to be already polluted by $7 \mu \mathrm{Sv} / \mathrm{h}$ approximately as shown in Figure 4.

The relative radioactivities on the ground surface estimated with the ISOCS software were 100 for ${ }^{132} \mathrm{Te}$

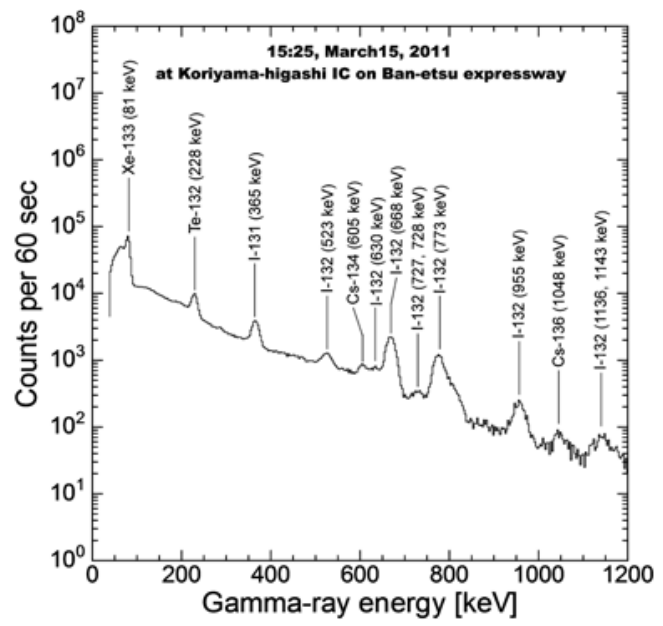

Figure 2. $\gamma$-ray spectrum measured with $\mathrm{LaBr}_{3}$ detector [1]. 
(normalized), 78 (minimum) to 128 (maximum) for ${ }^{132} \mathrm{I}$, 5 to 396 for ${ }^{131} \mathrm{I}, 12$ to 27 for ${ }^{134} \mathrm{Cs}$, and 3 to 8 for ${ }^{136} \mathrm{Cs}$ on the days from March 15 to 17 . Since ${ }^{132}$ I was the equilibrated daughter of ${ }^{132} \mathrm{Te}$, their radioactivities were very close to each other. The radioactivities on April 8 were normalized to ${ }^{137} \mathrm{Cs}$, since ${ }^{132} \mathrm{Te}$ already disappeared. The relative values were 100 for ${ }^{137} \mathrm{Cs}, 5$ to 33 for ${ }^{131}$ I, 101 to 103 for ${ }^{134} \mathrm{Cs}$, and 5 to 8 for ${ }^{136} \mathrm{Cs}$.

Figure 5 shows the trends of exposure rate measured with active personal dosimeters worn by Uwamino (red)

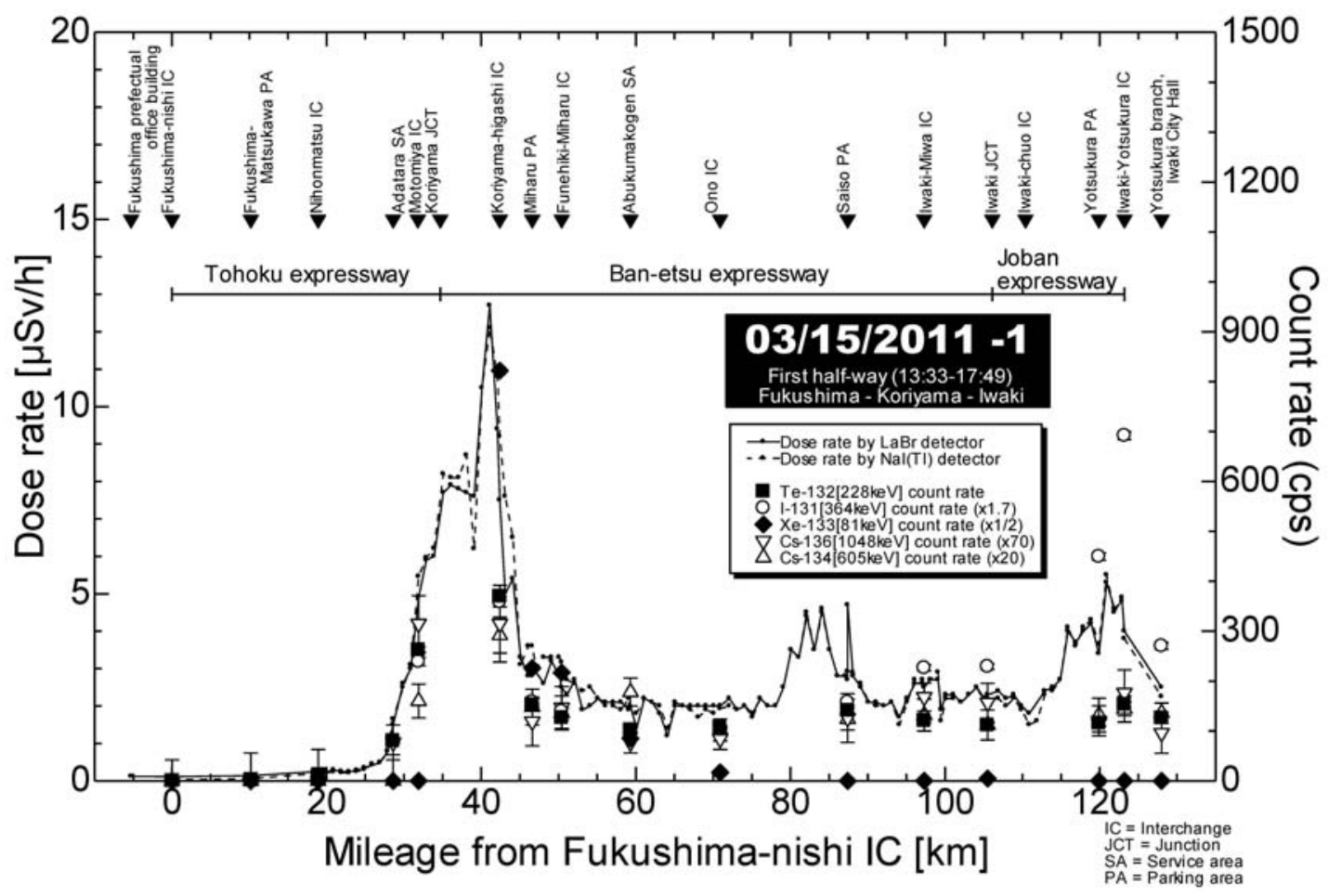

Figure 3. Measured distribution of the dose rate and the $\gamma$-ray count rate on March 15, 2011 (the first half-way) [1].

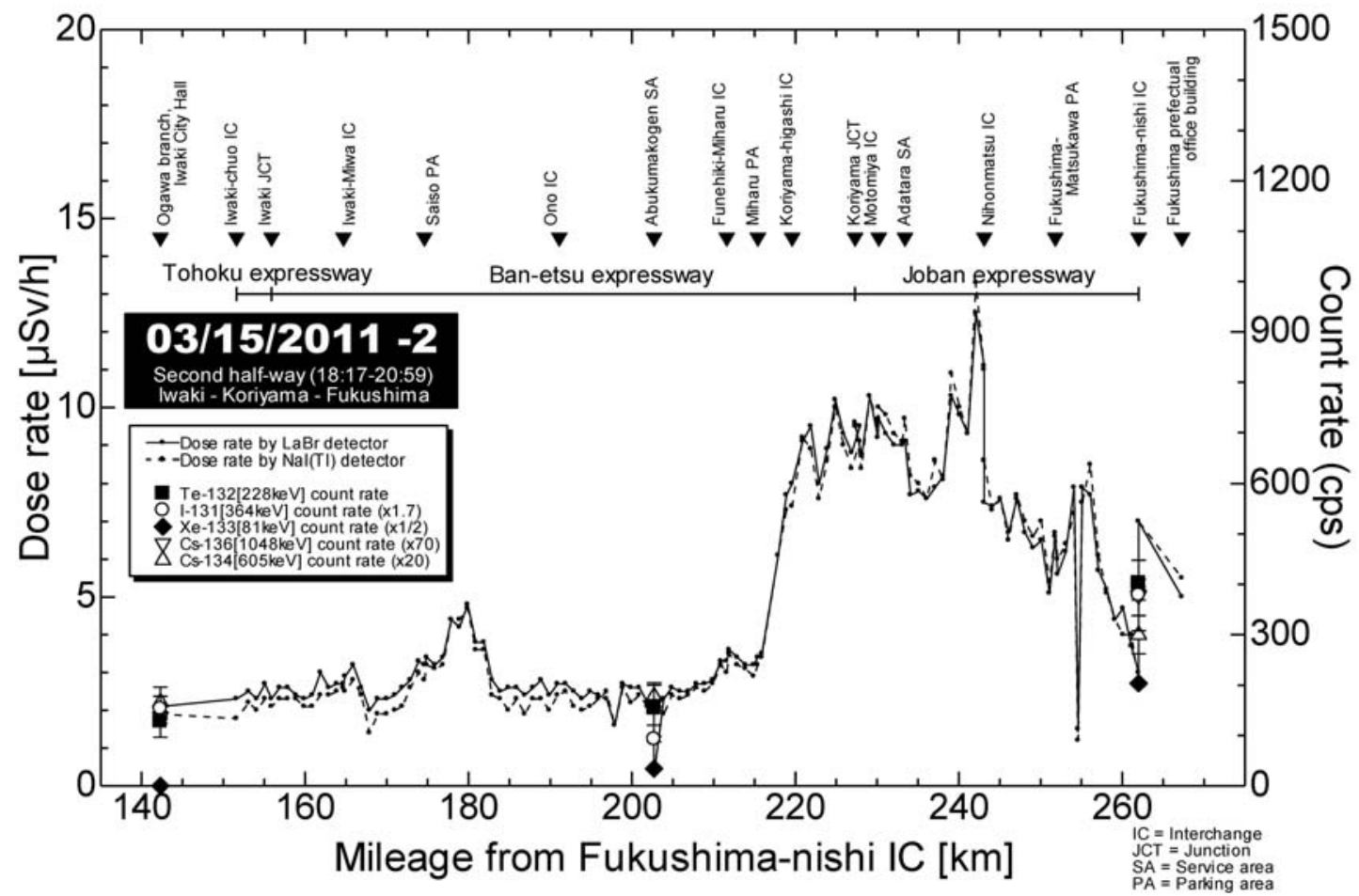

Figure 4. Measured distribution of the dose rate and the $\gamma$-ray count rate on March 15, 2011 (the second half-way) [1]. 


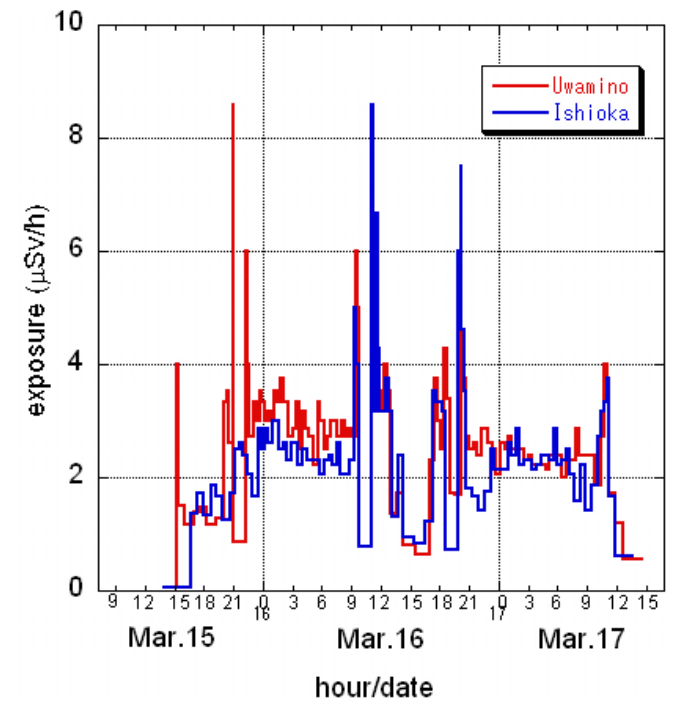

Figure 5. Exposure rate of Uwamino and Ishioka measured with active personal dosimeters. Ishioka stayed in Fukushima city on March 15.

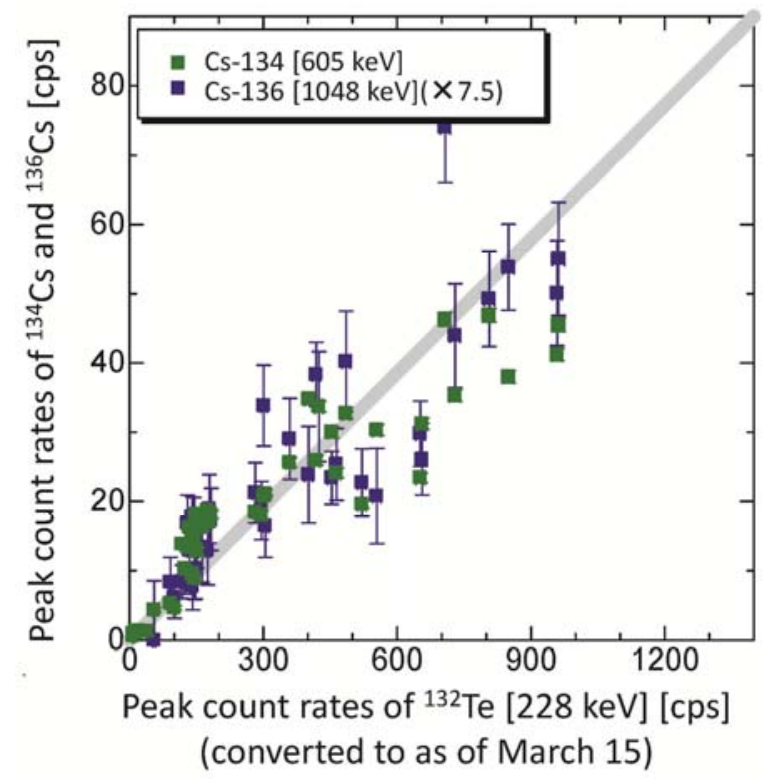

Figure 6. Correlation between count rates of ${ }^{134} \mathrm{Cs},{ }^{136} \mathrm{Cs}$ and ${ }^{132} \mathrm{Te}$ [3].

and Ishioka (blue). Since Ishioka stayed in Fukushima city on March 15, the blue line shows the dose rate in a wooden house in Fukushima city on 15. It was found that the radioactive plume reached Fukushima city at about 4 p.m.

From the measurement on April 8 it was found that the relative dose distribution did not changed. The attenuation of the absolute value was explained as the decay of the radionuclides. This implied that, at the measured area, most of the radioactive material was deposited with the rain and snow on March 15, and that there was effectively no additional deposition after March 15.

The dominant radionuclides in terms of the dose rate were ${ }^{132} \mathrm{Te}$ and its equilibrating daughter, ${ }^{132} \mathrm{I}$, on March

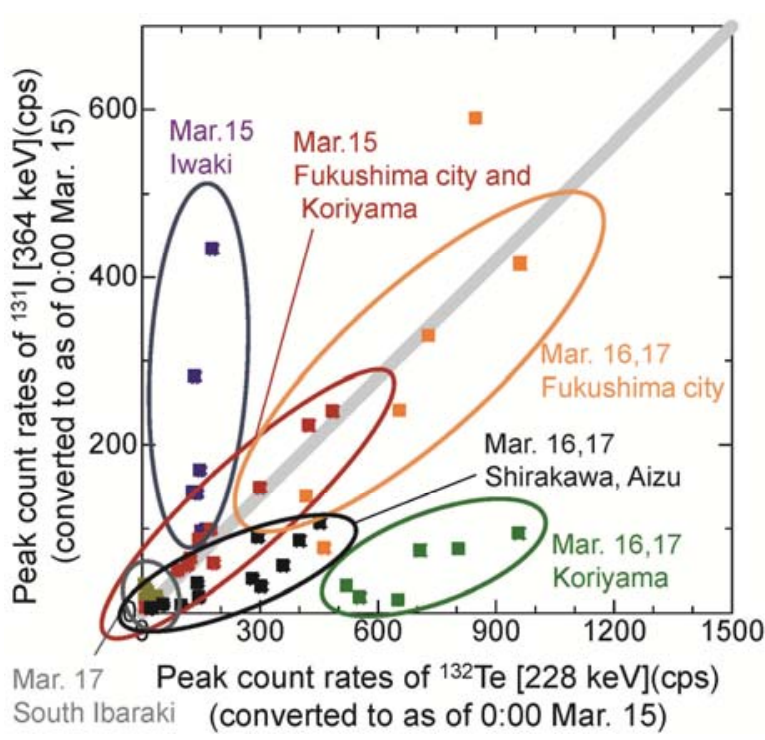

Figure 7. Correlation between count rates of ${ }^{131} \mathrm{I}$ and ${ }^{132} \mathrm{Te}$ [3].

15 to 17 and ${ }^{134} \mathrm{Cs}$ and ${ }^{137} \mathrm{Cs}$ on April 8 .

Figure 6 shows the strong correlation between the distributions of ${ }^{132} \mathrm{Te},{ }^{134} \mathrm{Cs}$ and ${ }^{136} \mathrm{Cs}$, and it can be said that these nuclides behaved similar way. On the other hand, the distribution of ${ }^{131}$ I showed different pattern from the others as shown in Figure 7. This can be explained by the different mechanisms of depositions, that is, most elements are deposited by rain and snow, while iodine easily deposits in a dry condition.

\section{References}

[1] H. Matsumura, K. Saito, J. Ishioka and Y. Uwamino, Diffusion of radioactive materials from Fukushima Daiichi Nuclear Power Station obtained by gamma-ray measurements on expressways, Nihon-Genshiryoku-Gakkai Wabun Rombun Shi (Transactions At. Energy Soc. Jpn.) 10 (2011), pp. 152-162. [in Japanese]

[2] H. Matsumura, How was the situation of the scattered radionuclides in Fukushima Hama-dori right after the accident of Fukushima Daiichi Nuclear Power Station, http://rcwww.kek.jp /hmatsu/fukushima/ (2011). [in Japanese]

[3] H. Matsumura, K. Saito, J. Ishioka and Y. Uwamino, Characteristics of distribution of radionuclides from Fukushima Daiichi Nuclear Power Station in Fukushima prefecture and neighbor prefectures obtained by a gamma-ray measurement immediately after the accident, 55th meeting of the Japan Society of Nuclear and Radiochemical Sciences, Nagano (Sep. 2011), J. Nuclear and Radiochemical Sciences 12 Suppl. (2011), p 22. [in Japanese]

[4] Canberra Industries, Inc., Model ISXCLLA1, $1.5 \times 1.5 \mathrm{LaBr}_{3}$ Detectors, Characterization Report 9241263A, Canberra Industries, Inc. (2007). 